with main component of the device: photometric sensor and principle based on the works by Ellman. By a non-probabilistic sampling, we recruited 190 farmers from the two townships fulfilling all the inclusion criteria and available to participate to all stages of the study.

Results The studied population is essentially young: $83.16 \%$ were under 45 years old, with $75 \%$ illiterates. $70.3 \%$ of the farmers have more than 10 years of spraying experience. We noted that $2.06 \%$ of the farmers still used domestic containers to prepare the pesticides. As precautions to prevent poisoning after spraying, $10.31 \%$ of the surveyed farmers drink milk. There was a significant AChE decrease between pre-exposure (AChE 3.08 $\pm 2.3 \mathrm{UI} / \mathrm{ml}$ ) and post-exposure (AChE 2.65 $\pm 0.52 \mathrm{IU} / \mathrm{ml}) ; \mathrm{p}=0.009$. $73.1 \%$ of the famers were concerned by that inhibition. Those who could read the pictograms faced less inhibition of AChE $(p<0.05)$. The age variables, level of education and experience of pulverisation do not have any influence on AChE inhibition.

Conclusion AChE monitoring is needed for the surveillance of farmers.

\section{RISK PERCEPTION AMONG MIGRANT AGRICULTURAL WORKERS}

Antonio Valenti*, Benedetta Persechino, Bruno Maria Rondinone, Grazia Fortuna, Valeria Boccuni, Sergio lavicolo. Inail, Monteporzio Catone, Italy

\subsection{6/oemed-2018-ICOHabstracts. 1358}

Introduction Over the past few years, there has been a progressive increase in foreign labour force in agricultural sector in Italy, which has reached over 115000 units $(14.2 \%$ of total employment in agriculture), of which $36 \%$ coming from EU countries, while 64\% from non-EU countries.

In case of migrant workers factors such as lack of knowledge of occupational safety and health (OSH) legislation, language knowledge difficulties, young age, lack of information and training and, consequently, reduced perception of workrelated risks, could further increase the risk for health due to both specific risks of the activities carried out and the peculiar characteristics of the work organisation.

The present study aims at detecting the perception of $\mathrm{OSH}$ risk in agriculture in migrant workers as a contribution to the identification of training needs.

Methods With the support of cultural mediators, an ad hoc questionnaire was submitted to 402 migrant workers employed in agriculture in Lombardy Region.

Results The interviewees have different nationalities (60\% Indian, 15\% Moroccan, 15\% Bengali), with mostly seasonal employment contracts (96\%); the age most represented is 2534 years (41\%).

Over $56 \%$ generally evaluate their health 'very good'. About $73 \%$ of respondents believe that there are no risks for $\mathrm{OSH}$ and $80 \%$ of them believe that are not personally exposed. Over $62 \%$ is very/completely agree that the lack of knowledge and awareness of workers' dangers in the workplace contributes to an injury.

Conclusions Preliminary results of the study requires a secondary analysis in order to contribute to the implementation and optimisation of preventative tools in consideration of the peculiarities that characterise the agricultural sector.
583 EVIDENCE-BASED SOCIAL LEARNING FOR SAFETY AND HEALTH PROMOTION AMONG IRISH DAIRY FARMERS

${ }^{1,2} \mathrm{~T} \mathrm{O}^{\prime} \mathrm{C}$ (nnnor* ${ }^{2}{ }^{2} \mathrm{D}$ Meredith, ${ }^{1} \mathrm{~J}$ Kinsella, ${ }^{3} \mathrm{~J}$ McNamara. ${ }^{1}$ School of Agriculture and Food Science, University College Dublin, Dublin, Ireland; ${ }^{2}$ Rural Economy and Development Centre, Teagasc, Dublin, Ireland; ${ }^{3}$ Kildalton College, Teagasc, Piltown, Ireland

\subsection{6/oemed-2018-ICOHabstracts. 1359}

Introduction Farming is an occupation that incurs high rates of occupational injuries and illness, including fatalities. Internationally, legislative approaches to improve agricultural occupational safety and health (OSH) practices have been inconsistent in achieving those objectives. Many alternative initiatives to influence agricultural OSH practices have been developed, frequently emphasising information provision. In Ireland, evaluation of information provision approaches, such as classroom-based learning, has found that this is ineffective for improving agricultural OSH practices. However, peer-based learning using communities of practice (COPs), such as Teagasc dairy farmer discussion groups, presents a promising context for agricultural OSH promotion in Ireland.

Research has established the efficacy of farmer discussion groups for promoting adoption of novel technologies and production practices. Little research has been undertaken to assess whether they are effective for promoting agricultural $\mathrm{OSH}$ practices. This paper describes the extent to which Teagasc dairy discussion groups engage with agricultural $\mathrm{OSH}$, and identifies the characteristics associated with agricultural $\mathrm{OSH}$ engagement. The results are evaluated with respect to the existing literature regarding effective social learning for farming and $\mathrm{OSH}$ promotion, to assess the suitability of these COPs for agricultural OSH promotion.

Methods Information about discussion group characteristics and engagement with OSH topics was collected using a survey of Teagasc dairy discussion group members, and a survey of Teagasc dairy discussion group facilitators. The statistical software $\mathrm{R}$ was used to assess variation in discussion group engagement with $\mathrm{OSH}$, and the group characteristics statistically associated with that variation.

Result Analysis of the results is ongoing and will be completed in September 2017.

Discussion The findings of this study, including the evaluation framework developed from literature review, can contribute to effective agricultural $\mathrm{OSH}$ promotion in Ireland, and internationally. This is especially true for other countries with existing farmer COPs, such as farmer discussion groups in New Zealand and Wales.

\section{KNOWLEDGE, ATTITUDES, AND PRACTICES OF THE USER GARDENERS OF PESTICIDES IN BURKINA FASO}

${ }^{1}$ AV Hinson, ${ }^{2}$ MS Lompo, ${ }^{3}$ B Aguemon, ${ }^{1} \mathrm{H}$ Lawin, ${ }^{1} \mathrm{P}$ Ayelo, ${ }^{1} \mathrm{~B}$ Fayomi. ' Unity of Teaching and Research in Occupational Health, University of Abomey-Calavi (Benin); ' Unity of Training and Research in Health Science, Public Health department, University of Ouagadougou (Burkina Faso); ${ }^{3}$ Département de Santé Publique, unité de biostatistique Faculté des Sciences de la Santé de Cotonou (Université d'Abomey-Calavi Bénin)

\subsection{6/oemed-2018-ICOHabstracts. 1360}

Introduction Pesticides are very useful in the field of gardening for the fight against pests, which exposes gardeners to the risks associated with their use. The aim of our work was to study the 